\title{
Clinical and genetic peculiarities of vasculitis associated with Familial Mediterranean fever in Armenian children
}

\author{
G Amaryan ${ }^{1,2^{*}}$, T Sarkisian $^{3,4}$, A Tadevosyan ${ }^{5}$ \\ From 8th International Congress of Familial Mediterranean Fever and Systemic Autoinflammatory Diseases \\ Dresden, Germany. 30 September - 3 October 2015
}

\begin{abstract}
Introduction
Familial Mediterranean fever (FMF) is the most common hereditary disorder among Armenians. It manifests mainly in childhood and represents a significant health care pediatric problem. The clinical picture of FMF and vasculitis have much in common: fever, abdominal pain, arthritis, myalgia, skin lesions. Numerous data indicate a higher incidence of vasculitis in FMF patients, compared with healthy ethnically matched populations.
\end{abstract}

\section{Objective}

To investigate clinical and genetic peculiarities of vasculitis associated with FMF in children in Armenia.

\section{Methods}

A group of 715 children with FMF was observed at the National Pediatric Centre for FMF (438 boys, 277 girls, mean age $8.64 \pm 0.17$ ). The diagnosis of FMF was confirmed based on the Tel-Hashomer criteria and molecular genetic detection of MEFV mutations. For statistical analysis standard statistical Epi-Info 2000 Program was performed.

\section{Results}

Frequency of vasculitis in Armenian children with FMF was rather high - 4.3\% (31 children). Henoch-Shonlein Purpura (HSP) was diagnosed in 1.5\% (11) patients, Protracted Febrile Myalgia (PFM) - in 2.7\% (20). FMF in these patients characterized by early onset (mean age 3 years), high (4 fold) risk of PFM $[R R=3.90(1.32 \div$ 11.35); $\chi 2=5.94 ; \mathrm{p}=0.015$ ], as well as late diagnosis of

\footnotetext{
"Arabkir" Medical Centre-Institute of Child and Adolescent Health; Yerevan State Medical University, National Paediatric Centre for Familial Mediterranean Fever, Yerevan, Armenia

Full list of author information is available at the end of the article
}

FMF $(9.42 \pm 0.72)$ and late onset of colchicine treatment. They had also high frequency of severe FMF attacks, prevalence of acute recurrent arthritis and HSP and PFM manifestation after 5-6 year of FMF onset. The risk of HSP was 5-fold increased in children with severe FMF compared with moderate activity of disease. The development of vasculitis was associated with M694V-homozygous and compound-heterozygous genotypes. Particularly, HSP and PFM were observed respectively at $2.9 \%$ and $4.6 \%$ M694V-homozygous patients $(\chi 2=8.27 ; \mathrm{p}<0.02)$, which confirms the influence of $M E F V$ genotype on the development of vasculitis.

\section{Conclusion}

Armenian children with FMF had higher than expected frequency of vasculitis (4.3\%). We suppose, that in children with FMF: 1) HSP and PFM vasculitis might be considered as markers of severe FMF and early disease onset 2) M694V homozygous genotype is a risk factor for the development of PFM. These results are consistent with data on the susceptibility of FMF patients in ethnically matched populations in the development of HSP and PFM [Lange-Sperandio B. et al., 2004].MEFV mutation genetic screening is recommended for Armenian children with HSP, PFM vasculitis for early diagnosis of FMF, treatment and prevention of complications.

\footnotetext{
Authors' details

"Arabkir" Medical Centre-Institute of Child and Adolescent Health; Yerevan State Medical University, National Paediatric Centre for Familial Mediterranean Fever, Yerevan, Armenia. ${ }^{2}$ Yerevan State Medical University, Pediatrics, Yerevan, Armenia. ${ }^{3}$ Yerevan State Medical University, Medical Genetics, Yerevan, Armenia. ${ }^{4}$ Centre of Medical Genetics and Primary Health Care, Medical Genetics, Yerevan, Armenia. ${ }^{5}$ Yerevan State Medical University, Public Health and Health Care, Yerevan, Armenia.
} 

vasculitis associated with Familial Mediterranean fever in Armenian children. Pediatric Rheumatology 2015 13(Suppl 1):P91.

Submit your next manuscript to BioMed Central and take full advantage of:

- Convenient online submission

- Thorough peer review

- No space constraints or color figure charges

- Immediate publication on acceptance

- Inclusion in PubMed, CAS, Scopus and Google Scholar

- Research which is freely available for redistribution 